\title{
Packaging and its impact on environment : Challenges and opportunities
}

SURBHI CHITKARA AND SUSHMA GOEL

Article Chronicle :

Received:

12.11.2014;

Accepted :

24.11.2014

Key Words :

Packaging,

Environment

challenges,

Opportunities
SUMMARY : The term 'Packaging' is no more restricted to its basic functions like containment, protection, and preservation. Packaging plays an important and intermediate role in marketing. Packaging design must attract consumers in today's increasingly competitive and quickly changing market. Focusing on advanced technologies, the packaging industry is bringing in more innovationsto meet the demands of the customers. However, these innovations have also created a problem of accumulation of packaging solid waste in huge quantity, leading to environmental hazards. In the current days, rise in concern over environmental hazards, eco-friendly packaging, and waste reduction targets specified by other countries has been observed. Preventing packaging waste and minimisingits environmental impact is a complex task. Waste prevention should not be considered solely as qualitative and quantitative reduction of packaging materials, rather it must take account of the entire process chain - from production, distribution and sales to use by the consumer and subsequent disposal. Most packaging and containers are made from materials such as plastic, cardboard, glass and steel, which can be recycled easily and effectively. Recycling packaging diverts large amounts of waste from landfill and has many other environmental benefits. For instance, it takes about 84 per cent less energy to recycle a plastic bottle than to make one from raw materials. However, the market for recycled plastic products is limited due to inconsistency of the raw material. The rise in environmental consciousness in recent decades has included a focus on household waste. It is not the most urgent of the problems we face, but it may be the most immediately accessible. Garbage disposal happens again and again, right at home under our personal control. The problem of solid waste has expanded rapidly in recent times; most adults today remember growing up in a world that used much less packaging. There is an urgent need to look into some major aspects of packaging that are believed to have a negative impact on the environment. The participation of local municipalities and consumers as well as people in industry is extremely vital in addressing the problems impacting the environment.

HOW TO CITE THIS ARTICLE : Chitkara, Surbhi and Goel, Sushma (2014). Packaging and its impact on environment: Challenges and opportunities. Asian J. Environ. Sci., 9(2): 91-99.

\section{Author for correspondence :}

\section{SUSHMA GOEL}

Department of Resource Management and Design Application, Lady Irwin College, University of Delhi, NEW DELHI, INDIA Email: sushmagoel7 @ gmail.com

See end of the article for Coopted authors' 